Steuerberater-Jahrbuch 2006/2007 



\title{
Steuerberater-Jahrbuch 2006/2007
}

\author{
zugleich Bericht
}

über den 58. Fachkongress der Steuerberater

Köln, 26. und 27. September 2006

Herausgegeben

im Auftrag des Fachinstituts der Steuerberater von

Prof. Dr. Detlev J. Piltz Rechtsanwalt, Fachanwalt für

Steuerrecht
Dipl.-Kfm. Manfred Günkel Steuerberater u. Wirtschaftsprüfer

Dr. Dr. Ursula Niemann

Steuerberater

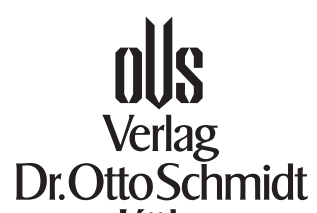

Köln 


\section{Zitierempfehlung:}

Verfasser, StbJb. 2006/2007, Seite

\section{Bibliografische Information}

der Deutschen Nationalbibliothek

Die Deutsche Nationalbibliothek verzeichnet diese Publikation in der Deutschen Nationalbibliografie; detaillierte bibliografische Daten sind im Internet über http://dnb.d-nb.de abrufbar.

Verlag Dr. Otto Schmidt KG

Gustav-Heinemann-Ufer 58, 50968 Köln

Tel. 02 21/9 37 38-01, Fax 02 21/9 3738-943

info@otto-schmidt.de

www.otto-schmidt.de

ISSN 0081-5519

ISBN 978-3-504-62652-5

C2007 by Verlag Dr. Otto Schmidt KG, Köln

Das Werk einschließlich aller seiner Teile ist urheberrechtlich geschützt. Jede Verwertung, die nicht ausdrücklich vom Urheberrechtsgesetz zugelassen ist, bedarf der vorherigen Zustimmung des Verlages. Das gilt insbesondere für Vervielfältigungen, Bearbeitungen, Übersetzungen, Mikroverfilmungen und die Einspeicherung und Verarbeitung in elektronischen Systemen.

Das verwendete Papier ist aus chlorfrei gebleichten Rohstoffen hergestellt, holz- und säurefrei, alterungsbeständig und umweltfreundlich.

Satz: Hain-Team, Bad Zwischenahn Druck und Verarbeitung: Bercker, Kevelaer Printed in Germany 